\title{
Article
}

\section{Observing Participants}

\section{Digital Ethnography in Online Dating Environments and the Cultivation of Online Research Identities}

\author{
Antonio Silva Esquinas, Rebeca Cordero Verdugo, Jorge Ramiro Pérez Suárez, \\ Daniel Briggs \\ Universidad Europea de Madrid
}

\begin{abstract}
This article offers a critical methodological reflection on how we undertook covert digital ethnographic research on Spanish young people and their use of online dating apps with a focus on the potential risk attached to using them. We were interested in showing how we approached the fieldwork, how we developed different research identities and how those identities were able to draw out raw data which reflected the risk attached to the online dating apps. While the project as a whole used a mixedmethods framework which also encompassed open-ended interviews and surveys, we provide a series of critical reflections attuned to digital ethnography. Thus, the purpose of this paper is to show how the methodological techniques cultivated 'identities' for our ethnographer that became effective in teasing out attitudes to risk and sexual exploration. We also hope that the paper can facilitate similar studies in the future, thus paving the way for other researchers. For this reason, we highlight the problems we encountered during the fieldwork and discuss the ethical issues related to this specific field.
\end{abstract}

Keywords Digital ethnography, criminology, app, methodology, online dating

'Fieldwork is an exercise of multiple roles [...] it is in some ways a masquerade' (Velasco and de Rada 2006)

This article offers a critical methodological reflection into how we undertook covert digital ethnographic research on Spanish young people and their use of online dating apps with a focus on the potential risk attached to using them. We are interested in showing how we approached the fieldwork, how we developed different research identities and how those identities were able to draw out raw data which reflected the risk attached to the online dating apps. We chose six dating apps commonly used by young people in Spain and undertook the study over the course of 12 months in 2018. Ethnographic studies on online dating apps are almost non-existent. Recent monographs focus instead on the role of the internet in dating (Daniels, Gregory and McMillan Cottom 2016; Smith and Duggan 2013), on men, masculinity and contemporary dating (Haywood 2018; Ryan 2016). In a similar vein, journal article authors tend to use theoretical approaches and/or quantitative surveys that focus on gender and identity (Clemens, Atkin and Krishnan 2015), online dating behavior 
(Huber and Malhotra 2017; Oliviola, Eastwick, Finkel, Hortaçu, Ariely, and Todorov 2015) and user experiences (Xia, Lui and Sun 2015). Certainly, the current research also ignores key features of using the apps such as harassment, violence and crime (Amnesty International 2017).

These works are without doubt valuable but do not uncover the ambivalence attached to using the apps or the commercial mechanisms which not only stimulate user interest but keep it residually active. This is an important area to consider given the rapid advances of neoliberal consumer capitalism and its onslaught on the commercialization of everyday life which nurtures brazen individuality, elevated attitudes to risk-taking and a promotion of self-gratification as a mode of being-in-the-world (Hall, Winlow and Ancrum 2008). For this reason, young peoples' subjective lifeworlds revolve increasingly around their sense of self, invites them to be impulsive in the satisfaction of their own desires (Lipovetsky 2003). They become more narcissistic (Bauman 2000) and this sense of immediacy and emphasis on image is played out on daily basis on apps like Facebook and Instagram which demand constant use, so the user's ideological sense of satisfaction and status is continually fed with attention and therefore supposedly contented.

We become products of our own consumption: 'walking products' which merely reflect the commercial ideology of the objects we are sold and 'manufactured to desire' (Žižek 2009). Young people play out these identities in increasingly artificial spaces or 'nonspaces' (Augé 2008): places such as shopping malls, duty free lounges and the like which are bereft of history, essence and personality. Participation in these spaces shuts us down from social life as we seek what Birtchnell and Caletrio's (2013) describe as a kind of 'oysterization' of the world around us; one that offers security, free-flowing access and closure, whenever these qualities are desired. This 'capsularization' of social life (De Cauter 2005) also evokes secure zones, private transport systems and protected leisure destinations, and function to produce privacy and safety as well as prestige. We close ourselves off from the outside world and all its associated dangers and problems or in the words of Byung-Chul (2017: 71): "These days, everything revolves around "I like". The absence of opposites is not an ideal state but the opposite because one suffers a hard fall in collision with oneself. It is this absence which drives us to self-erosion.'

The apps we focus on in this paper are those that offer dating services and access to a supposed freedom of sexual expression and exploration. While, to some degree this may take place, we have argued in other texts that their use represents the commodified assault on central aspects of our interactions, identity and intimacy. These apps, we suggest, produce and reproduce scripted interactions of ideologically manufactured desires which reflect a subservience to a commercial culture of personal indulgence and individualised risk-taking and pleasure-seeking (Silva Esquinas, Pérez Suárez and Briggs 2018). The way in which we undertook our study had to come to terms with the commercial ideology behind the apps because it was partly responsible for the diluted notions of gender and blurred sexual orientation and the commodified exploits to obtain as many sexual conquests as possible.

We found that our work was able to challenge these antagonisms given its immersive approach in the online forums and thus the life of the users. Similarly, there appear to be few empirical works which have shed light on the feelings associated with using dating 
apps and subjective disjuncture this creates. To analyze these issues, we designed a mixed-methods research system (Bryman 2012). The research was devised around three phases:

1.Digital ethnography and in-depth interviews

2.Surveys

3.Focus groups

For the purposes of this article, we focus on the area of digital ethnography. This technique was considered necessary for this research environment for three reasons: 1) we had to understand the context that we were studying from the inside: what the dynamics of action and inputs were, the subjects who socialized in them, and the problems within them, especially given that this knowledge could be used to arrange more effective interviews and questionnaires; 2) it was considered essential to understand the attitudes users of these apps first hand to obtain much more in-depth knowledge of the phenomenon than we would otherwise have got through external sources only; and 3 ) it was a very useful technique for avoiding the desirability bias, which in practice is present in surveys (Kvale 2008).

Therefore, we undertook undercover fieldwork for three months on six apps with different orientations: 1) Tinder; 2) Grindr; 3) Wapo; 4) Wapa; 5) Lovoo; 6) Badoo. While we write the article as a collective, only one of us undertook the fieldwork online. Our ethnographer firstly spent short, intense periods of observation in the forums (only reading exchanges) so he could learn about terms, practices, ways of interaction and obtain a general background. During this period, no interactions took place with forum members. When we held regular meetings to discuss approaches, the research team shared with the ethnographer ample context on articles they had read on sexual practices and sexual orientations. This acted to triangulate our research approach so that as we progressed throughout this phase, more particular terms relative to the forums were learnt along the way. In these online forums, the ethnographer worked behind eight different identities which encompassed heterosexual males and heterosexual females, homosexual males and females, bisexual males and females and heterocurious ${ }^{50}$ males and females. Over the period of three months, we managed to generate a total sample made up of $\mathrm{N}=800$ interactions, where the sub-sample $\mathrm{N}_{1}=310$ was composed of direct interactions. ${ }^{51}$

\section{Digital Ethnography}

Ethnographic research on online practices and communications, and on offline practices shaped by digitalisation, has become increasingly popular in the recent years with the growing influence and presence of the internet in people's everyday lives (Hall and Antonopoulos 2018). The rise of digital technologies has the potential to open new

\footnotetext{
50 By 'heterocurious' we mean those individuals who consider themselves heterosexual but like to engage in sporadic homosexual relations.

51 We have to note that when $\mathrm{N}_{1}=310$ direct interactions are indicated we are alluding to those in which there was a more or less prolonged conversational interaction. The $\mathrm{N}=800$ interactions are also composed of those in which there was no such conversation, but rather interactions through icebreakers, stickers, etc. We have not taken into account the numbers of likes, matches, etc. in the sample.
} 
directions in ethnography. In the anthropological and sociological52 literature, a number of closed definitions can be found on digital ethnography53 (Baym 1999; Ito 1997; Lyman and Wakeford 1999). Hine (2000) was the first to establish holistic definition to encompass digital ethnography briefly as the transfer of classical ethnographic techniques $^{54}$ to Information and Communication Technologies (ITC). Definitions continued to evolve and ten years later Kozinets (2010) proposed the following definition of what she called 'Netnography': 'A type of online or internet ethnography; netnography provides guidelines for the adaptation of participant-observation procedures to the contingencies of online community and culture that manifest through computer-mediated communications' (Kozinets 2010, 191).

Recent other examples also show efforts researchers have made in this field. In their Digital Ethnography: Principles and Practice, Pink, Horst, Postill, Hjorth, Lewis, and Tacchi (2016) offer alternatives. They base their proposal on innovation and the creation of new techniques on the grounds that classical ethnography and its closed definition have become obsolete in the face of the changing reality of ICT. They find it more practical to establish a series of criteria that all digital ethnographies should encompass yet without involving watertight definitions and permit the freedom to adjust to the field of study. It is also useful to remember that ethnography is conditioned by the area of knowledge of the ethnographer, by the objectives of each particular research project, by the organization funding the research, etc. In this respect, it is more useful to understand it as an adaptive process rather than as something finite (Pink, Horst, Postill, Hjorth, Lewis, and Tacchi 2016).

\section{Covert Digital Ethnography}

A substantial proportion of digital ethnography seems to be covert, a trend which has produced some enlightening studies over the last 20 years. Slater's (1999) work on Internet Relay Chat (IRC) studied the exchange of 'sexpics' and digitally encoded 'sexually explicit material' among a number of users over the course of a year. Slater's covert participation in 'sexpic' chat groups found that the digital sex image serves as a barter currency (e.g. to be exchanged for similar or other types of pornographic computer files) between users in this community. Sharp and Earle (2003) covertly studied paid-for-sex on the internet by looking at over 5000 'reviews' by male clients of sex workers on a 'punters' website. They carefully mapped the network, examining the cognitive and spatial dissonance and consonance between those who placed the reviews. Magnet's (2007) study of the website suicidegirls.com - a commercial site featuring nude photographs of 'heavily tattooed, punk women'. All of Magnet's work was undertaken online and the bulk of her digital ethnographic data came from the site's well-trafficked

\footnotetext{
52 Although it is true that we also find it in other areas such as computing itself or information sciences and communication (Pink, Horst, Postill, Hjorth, Lewis, and Tacchi 2016).

53 As we will see, depending on which author we consult we find different words for defining this type of ethnography, ranging from the virtual ethnography of Hine (2000) to the netnography of Kozinets (2010) and digital ethnography of Pink Pink, Horst, Postill, Hjorth, Lewis, and Tacchi (2016).

54 As an example, we have the definition of classical ethnography that Angrosino proposes as 'the art and science of describing a human group - its institutions, interpersonal behaviors, material productions, and beliefs [where] ethnographic researchers are primarily concerned with the routine, everyday lives of the people they study' (Angrosino 2007, 35).
} 
forums, with the rest via e-mail interviews. Similar approaches were used by Gehl (2018) in his covert digital ethnography that studied the dark web. In all of these cases, we see the approaches making use of what Ebo (1998: 3) terms 'cyberstealth' - a way of covertly reading web blogs and/or taking on anonymous web 'avatars' in chat rooms or forums.

\section{Fieldwork Strategies: Logging On}

As we will see, these techniques were useful to us in our endeavors to draw out the risk attached to the online dating apps. However, before we began our fieldwork, we required some time to learn about the forums in which we were about to enter.

\section{Prior Observation}

Prior to the study, none of the researchers had knowledge of the apps, who their target audience were, under what terms users communicated with others or what security measures were incorporated. Firstly, we selected four apps following two key criteria: a) the number of users in Spain; b) the target public at which they were aimed. These four apps were: 1) Tinder; 2) Grindr; 3) Badoo; 4) Wapa. This ensured that in each app the ethnographer would adopt a heterosexual male identity (Tinder) and heterosexual female one (Badoo), as well as someone posing as a homosexual male (Grindr) and a homosexual female (Wapa). We then had to create false email accounts and then download the apps but realized that these apps were limited in terms of gender and sexual orientation. For example, at the time, we not aware of the importance of bisexuality. We were also unaware that people were "heterocurious" in that we later found both bisexuals and heterosexuals searching for trio relations. For this reason, we expanded our sample to include two more apps.

The companies that own the apps each want an economic return and this they base to a certain extent around the sexual orientation of each interest group. Tinder was the most marketed app in which we were offered free services that were limited, and each extra service represented a financial cost for the user. Thus, to become a user with a high status that had control over where they could "geolocate" themselves, receive updates on potential "perfect matches", receive an infinite number of superlikes, appear in pole position in the photo galleries, etc. required us to spend around €16-26 every month, or pay for each service individually; the latter being more expensive. However, we realized that by paying more, we were essentially buying our own privacy and security - which was one main reason why we found that many users had false names/profiles.

The other apps had relatively similar dynamics to Tinder although the prices were generally lower. In some, it was possible for us to obtain credits if we undertook certain parallel activities (e.g. give a specific number of likes, subscribe to an online gaming platform, bet on one of the online betting sites, etc.). However, by far the most characteristic element of the apps was how they produced libidinal incitation by constantly "inviting" us to upload more photos, update our status to the community to position us better in the gallery of images or buy more credits so that our status and profile would appear more popular. Even in the case of Lovoo and Badoo we were immediately inundated with notifications such as: 
'Have you been in love? Attract the people you really like [options: spend 50 credits or send a video]

'You need 50 credits to improve your results. Recharge your credits and remember that the more you buy, the cheaper it will be!'

In the words of one of our participants, the apps operated as 'shop windows for sexual consumption' [Transcription of a Lovoo chat session]. We were offered the possibility of choosing a tailor-made profile-as-product (age, weight, height, eye color, urban tribe, whether smokes or drinks, HIV status, children, marital status, sexual orientation, physical complexion, sex role, etc.), and entered the variables in a search engine thus offering projecting ourselves in the forums. There was also the use of nicknames and descriptions that on many occasions told us clearly what was being offered or searched by each user. We found usernames such as 'Guzzler', 'WantSexyGirlForTrio' and 'emoticons: baby's bottle, lips, banana, three drops and a closed fist'; as well as profile descriptions such as:

Yes, I like sessions with drugs, but only one-on-one, no trios or orgies. I'm looking for quality and quantity. I'm looking for someone special to experiment with more sexual fantasies but who is not obsessed with sex. There are more things! [Fragment of Grindr description]

All we were asked to secure our account was:

-An email or phone number

- A photograph 55

-Verify our account by validating the photo with the technical team

- Fill out at least $60 \%$ of our profile

Practically none of our sample seemed to have had their accounts verified: there were no end to erotic photos, false and duplicated photos, etc. And unless we paid extra money to disable our geolocation, it was very easy for someone to monitor our activities.

\section{Profile Creation and Interaction}

Once we had undertaken a period of observation, we decided to start to form our research identities. The aim was to determine what type of impact we could generate in the online communities using the level of exposure of our profile and our own interactions.

\section{First Phase}

During the first stage, we gave ourselves random nicknames. At times it was a first name while at others it was simply random emojis without any relationship between them or words that maybe were suggestive or otherwise. These interactions did not result in significant conversations partly due to the limited nature of our profile. However, over time, we came to learn that these kinds of profiles were maintained by casual users of the apps who tended to have these more general profiles, used the app to monitor or

\footnotetext{
55 We should note that most apps establish a filter that does not allow photos with a sexual content though, as we were to find out, there was no real regulation of this.
} 
follow others and wanted to remain anonymous. Their nicknames therefore were indicative of nothing in particular.

\section{Second Phase}

For the second phase, we introduced a profile description and started our conversations based on the following descriptions:

1.Random descriptions without apparent sense (e.g. a black emoji of a Sevillian woman; an ellipsis; 'hi friend'; 'whassup').

2.Standard descriptions of our tastes or interests without alluding to absolutely anything related to sex or eroticism (e.g. 'I like outdoor sports, reading and the cinema"; "27 years old, a Marvel fan and fanatical about my work')

3.Descriptions that could denote a double meaning or sexual provocation (e.g. 'I'm fun, fitgirl without limits and I'm crazy about dancing. Can you keep up with my rhythm? [Emoticon with a wink and a tongue sticking out]'

4.Explicit descriptions targeted at demands of a sexual and/or drug-related nature (e.g. 'I'm looking for a passive man who likes poppers so I can open up his arse'; 'No Meth, no party'; 'is there any WOMAN (or MAN, depending on the app) who can really take it?')

5. This strategy allowed us to evaluate how this information was interpreted by the respective community. While we did not find a direct correlation between the level of explicitness and number of interactions, we did find qualitative differences. When using 1 or 2 , the interactions were in general more friendly to begin with 56 and not directed at sex from the start. As 3, users tended to enter into an interaction by alluding to an element of the description and directing it quickly to a sexual theme; however, not all of them ended up abandoning the conversation if we did not follow their sexual suggestions. In many cases this resulted in flirtations which gave rise to profound conversations. Using 4 had instant effects as interactions were direct and involved the exchange of pornographic images and videos. We found that when we lead these conversations in an aggressive way, it would trigger a role play with the user.

\section{Third Phase}

In the third phase, we introduced a 'neutral photograph'. The aim of this was to measure the stimulus of both the apps (our positioning in the gallery ranking) and how users related to us visually. The photographs were generally of a face, although at times we also used memes, landscapes, etc. We found that, the mere presence of a profile photograph helped to make the conversations more prolonged in the sense that it gave a certain feeling of security to the other user. However, we were often asked for more

\footnotetext{
56 But this is in general, as we continued to receive constant 'prick-photos', for example. Also, when we say "at the start" it is because although the start could be friendly, within a short space of time the topic became directed to sex, and if this path was not followed in the chat we were ignored or blocked.
} 
photographs or proof to verify that we were who we were. In general, because of the photo, we found that our conversations became more explicit.

\section{Fourth Phase}

Finally, during the last phase, we added to our profiles an explicit photo or the possibility of obtaining one by directly asking us. This was undertaken to build on the explicit conversations we and explore the nature of risk and vulnerability in more depth. We found that this was key to ensuring access to more raw interactions around drugs, risky sexual practices, violence and minors.

\section{Masquerading}

With these descriptions in mind, we then went about the forums masquerading these particular identities. How then were we able to appear given the verification processes attached to the apps? As stated earlier, the apps security mechanisms were extremely vulnerable. Becoming a verified user by the app simply meant that the technical team matched uploaded images with the owner of the app. This was generally done by sending a photo showing a card with some specific letters or by taking a selfie from the app itself so that a technician could compare it with those we had previously uploaded. Although this approach exacerbates vulnerability, it is a relatively effective filter, so where is the problem? Most of these community users do not verify their user profile, and so this practice becomes the norm thus enhancing the possibility of 'Catfishing' (Amedie 2015) or luring someone into a false relationship using a fictional character.

The apps ineffective security measures meant that users generated alternative means of guaranteeing that their safety/security by asking them for images of their face, an Instagram link, and/or a video or audio to confirm their identity. In addition, many sought to continue the contact by WhatsApp and/or asked for a photograph with the day's newspaper and specific letter code. The strategies of the former were relatively easy to deal with by taking two or three images of the same person and generating an Instagram account with images where the face was not visible. Many users also simply assumed the identity of another user with whom they had exchanged photos as we found images regularly replicated in these interactions. ${ }^{57}$ In any event, they were not effective strategies. In contrast, the request for a video or audio made it more difficult for us to maintain any our masquerade. In these cases, we either used voice modulators, videos that showed our legs, the room we were in, etc., without focusing on our face.

The WhatsApp measure caused real difficulties for us since it was common that after a few minutes of chatting online, we would be often asked for our phone number to continue the chat. This represented a major limitation for us because not all mobile devices could download WhatsApp. Secondly, because the virtual numbers were generally foreign, when we exchanged a Spanish number, it raised suspicion. We therefore refused to continue discussions through WhatsApp, telling the users that we had 'had bad experiences' having done so in the past. Most of the community appeared to understand this with respect to the chat.

\footnotetext{
57 In fact, it was a very common strategy to detect false accounts by recognizing the photographs that had been sent to us earlier from another account and/or app.
} 
The way we masqueraded differed significantly according to each conversation and context. Sometimes we had to talk with affection while at other times lasciviously or playfully or directly. The slang we used was typically used within the app itself and we learned about this as we spent more time in the online forums of the apps (Estalella, 2018). In this way, we were able to mirror the type of character the other was; we talked the same language they did and in the tone they wanted or rejected. We were capable of being someone in love, inaccessible, out of touch, direct etc. and all this allowed us to access a catalogue of rich data. In addition, when we became involved with an aggressive, cocky, histrionic, narcissist, character we found it useful to study the reactions, needs and desires, etc. in line with the identity we were projecting.

\section{Aggressiveness:}

Ethnographer: I will douse my prick in cocoa or meth and choke you with it $\mathrm{u}$ bitch

Zumba: Uffffff I love it// and in ur ass 2. [Fragment of a transcript from Grindr]

In this short exchange, we are leading the direct and aggressive nature of the conversation and introduce the idea of the use of drugs to which the user Zumba plays along with and even reciprocates. In many aggressive interactions, such suggestions are mirrored by users/by us. The choice of words are important in this respect as they lead help the user visualize the fantasy under construction. It was in these contexts that we were able to tease out responses related to attraction/excitement of risk:

Ethnographer: "What a whore you are, I like it without protection [without a condom], but I don't know if you will take the risk. I am HIV positive." [Sends naked picture with penis erect]

Adrian: "Mmmmmmmm how exciting! You being like that makes it more disgusting."

Ethnographer: "You like that I am HIV positive, bitch? You are too, right?"

Adrian: "Impregnate me as much as you like, until you are dry. I want your dick inside my arsehole...." [Chat from Grindr]

\section{Affectionate:}

Ethnographer: [...] // my little baby // cream puff of caramel-coated almonds with strawberry syrup // my straciatella ice-cream filled with icing sugar and shaved toffee

Voluptuous: He says my little baby hahaha [heart emoji] // ayyy // you make me feel good ${ }^{\wedge}$ // I'm heading back home and I'm hungrier for you than I could believe. [Fragment of Wapa transcript]

In some circumstances, if the user profile did not give us a clue, then we had to work out which type of identity to use. Here we are concluding an exchange with Voluptuous who we sense we are getting to know quite well. The poetic declaration we make is reciprocated for her desire for the interactions to continue. 


\section{Defensive:}

ActiveMan: [...] but look it's fine if you want to give that as an excuse and miss out on a huge dick and a fuck that you'd get from very few in your life like that and for hours...

Ethnographer: Your alpha male postures are useless, you're like MHYV [Spanish couples TV program] clones. What is disgusting for me or not is for me to decide not you. Do you have a big one? Yes, so what... nothing that so many others haven't offered or that any dildo can't give you. You should be a little more mature since you are so close to your thirties, macho man... [Fragment of Lovoo transcript]

Here we posed as a young woman. The exchange shows how we were also able to challenge to some degree macho male bravado as a means of adding a critical appreciation of the data which is why gender identities were also important to consider. During the fieldwork we found a broad spectrum of genders that covered heterosexual, homosexual, bisexual, polyamorous, heterocurious, and other non-binary constructions. This perspective of plurality and liquidity, freedom of choice without (or with less) fear of being judged. We found people that wanted to explore their sexuality to various extremes:

Pepper: [...] I'd like to do everything // why set yourself limits, no?

Ethnographer: I don't judge you, I'm bi. But I'm curious 2 know about you.

Pepper: Well, about everything you imagine, haha // I also fancy a trio and to eat your balls while you screw her // and then eat your cunt out after coming inside // hahaha. [Fragment of Lovoo transcription]

In this exchange we had with Sharon, a heterosexual woman, she is looking for another woman to undertake a 'threesome' with her boyfriend through the lesbian app, Wapa:

Sharon: Have you done a trio once?

Ethnographer: Only once. To do one with you I need to feel comfortable with the two people and you as well. If not, I don't like it. You?

Sharon: "I hope to do it with you," [smiley emoji x2] [Fragment from chat from Wapa]

However, within these gender constructs there were further antagonisms such as "gay on gay homophobia", "machophobia", "homophobia", "butchphobia" and numerous other derivative terms that became apparent so comments like this were commonplace:

R: Machos like you are what I need. The other ones are all limp. [Fragment of a transcript from Grindr]

We also found a shift in the spectrum of sexual appetite that adhered to the heteropatriarchal patterns. For example, the vast majority of female homosexuals demanded sublime female otherness and rejected those who had some kind of male physical features. The same happened with other homosexual males who continuously searched for other active males that were not affectionate and, if possible, heterosexuals. With 
respect to the heterosexuals, bisexuals, the polyamorous and non-binaries, as a general rule they continued to reproduce the dominant cultural patterns of sexuality for any gender; although the heterosexuals were more open to bisexual practices.

We therefore had to understand what each user felt in a context of erotic/festive courtship: in other words, when a person felt risk, fear, trickery, seduction, pleasure, anxiety, humiliation, etc.; as well as understanding the techniques and user preferences and the level of risk level some were prepared to assume.

\section{Geolocation}

Geolocation means: a) knowing the distance between us and those with which we chat; b) selecting people in our area due to ease of instant physical contact; and c) obtaining assignations with people in other places to which we may be traveling. This locational element permits significant risk to potential users as we have already seen in cities such as Madrid which has witnessed murders from someone using an online dating app, who came to be known as the 'Grindr killer' (Cedeira 2018). Another issue fostered by geolocation is that people in our geographical environment could forcibly take us out of the anonymity of our sexual condition and harass us. This happened on a number of occasions on which we became cautious that we were being watched:

Zee: You're close, I can smell you [tongue emoticon]. [Fragment of Wapo transcription]

Since we did not pay premium charges to control geolocation, it became typical that these types of messages could suddenly appear in a chat. In some apps, instead of offering a precise geolocation an approximate one was permitted. This can be useful in a large city, but in a small town it is limited; other apps allow you to 'cancel' it - and we put it in inverted commas because what they actually do is to geolocate all users in the center of Madrid. Had we paid money, we could disable our geolocation or even locate ourselves wherever we wanted. Three possible options appeared to us:

1.Access the apps that managed to use a patch from another app, giving us access to the premium functions (and thus to selective geolocation) without prior payment.

2.Connect our mobile to a WiFi network using a proxy.

3.Convince the other user that we are in one location temporarily and claim that there is a fault in the app (and immediately send a photo of the place where we supposedly are and with the weather conditions at the time). Equally, we could set it to 'travel mode'.

In this way, we guaranteed that our geolocation was not something that prevented us from undertaking our digital ethnography.

\section{Data Collection}

Each ethnographer has a different way of gathering data; there is no one standardized or more effective formula, so each ethnographer follows the method that is most effective for him or her (Díaz de Rada 2011). The most recognized means are drafted in a field notebook (whether physical, electronic, memory, etc.) so that all the detailed information can be transferred as soon as possible into a field diary (Hammersley and 
Atkinson 1994). The practice of keeping a field diary up to date was an essential element in our experience, as we described in detail everything that happened each day. This proved essential when we noted in the transcription process that suddenly we were missing chats in the records of some apps. Imagine the ethnographer's stupefaction on seeing that chats - which in this case represent valuable data - had been 'lost'. In fact, we noted that once some of the false accounts that had been created (above all those used for the sale of toxic substances and related to prostitution) were deleted they disappeared from the chat records. However, there were others that we seemed to have been deleted but yet we still had the chat in the records. Subsequently, we noted that this was because we had been banned from the forums. To avoid this from happening, we copied and pasted all the conversations we could soon after having them and saved them along with the photographs before they were lost/deleted by the app.

\section{Limitations}

The most important objective limitations we faced were that the Tinder app would not permit direct contact with users through the app. Another objective limitation from the start was the use of the profile photos. What photo should we use? One of our research team? A copyright-free image? And what about images that were a little risqué? The question of the use of images was one of those that presented most problems for us due to legal and ethical issues. In practice, we ended up using copyright-free photos, photographs of famous people and photographs that we had detected in more than three different profiles. Lastly, another limitation was that we could not explore the premium experience in all the apps for financial constraints.

Similarly, there were ethical limitations. As Hammersley and Atkinson state: 'The ethnographer participates openly or covertly in the everyday lives of people during a relatively extensive time, observing what happens, listening to what is said, asking questions; in other words, collecting all types of accessible data to throw light on the issues that he or she has chosen to study' (Hammersley and Atkinson 1994, 15). Ethnographic research has generated a great deal of controversy; to the point that it has become increasingly unpopular since the 1960s or 1970s (Bloor and Ward 2006) because of the increasing influence of policy-informed orientations of criminology and the domination of standard methodological toolkits used by criminologists which serve to fetishize quantitative methodology (Calvey 2013). So according to these strict canons, anything we did which was ethnographic would be faced with a violation of the ethics of social investigation (Angrosino 2007). However, in Spain, these issues have not come to the attention of the ethics committees as it is rare that ethnographic research is practiced here. However, as defended by Adler and Adler: 'Observers are reminded that they must take into account the right of subjects not to be manipulated when they weigh up the potential benefits of the role of investigation against the harm that could arise from it' (Adler and Adler 1994, 389). And the fact is that during this study the potential benefits were high 58 because we proceeded with extreme care in the collection and handling of data. Our image bank was destroyed once the analysis phase was

\footnotetext{
58 We tried to trace preventive policies not only aimed against victimization by physical, psychological or sexual aggressions, but also the transmission of STDs, drug dealing or pimping; taking into account that part of the sample was actually composed of minors. In the case of minors, we limited ourselves for ethical reasons to confirming that they were minors and ending contact with them.
} 
completed; the real names of the users and their phone numbers were only known by the ethnographer and replaced or deleted in the transcriptions so that they could not be located. In addition, the nicknames were anonymized so they did not correspond to the original ones. Finally, in terms of the treatment of the subjects of the research, given the way in which people converse in the forums, we felt that our conversations were entirely normal and to be expected and did not cause stigma or any trauma to the participants.

Finally, the ethics related to the use of explicit and/or pornographic photos also require attention. In our case, those we used came from public image banks in which no faces appeared (e.g. www.michocho.com). However, is it ethical to use them anyway for the ethnographic process? In our opinion, we consider that in the field in which we were working, where it was a normal practice to share porn photos/videos, it did not constitute an ethical malpractice but another method of communication in the field; just as using aggressive and/or sexual slang when the other users demanded it of us.

\section{Discussion}

This article has presented details of the methodological procedure followed in the digital ethnography phase of our research project on online dating apps. Its purpose is to show how we went about our study, how we established different identities and how, in this way, we were able to obtain rich data from the online app forums. We hope it can also act as a useful contribution in the Spanish criminological community for the development of future online investigations that make use of ethnographic methods. We have described what we wanted to do, how we did it and ended up having to do it and concluded with some reflections on the limitations. In turn, we are aware that this article acts more as a blueprint for future researchers rather than representing the full analysis of the results of the investigation. However, we understand that there may be insufficient context or data relating to the final analysis of the project preventing the article from being more complete but we aim to put right this limitation with the publication of the final results of the research.

In the article, we show the process connected to undertaking this digital ethnography which sought to look at Spanish young peoples' use of the online apps in the context of risk. The identities which we inductively cultivated through the different phases allowed us to tease out attitudes to risk and sexual exploration, and thus permitted us to obtain rich data acting as others have done before us using a form of 'cyberstealth' (Ebo 1998). Having gained experience using these identities, we were then able to be more proactive and critical in our interactions, and interrogate particular attitudes. We do not discount the ethical issues related to this terrain but tried to ensure that our interactions minimalized harm to our participants at all times.

With respect to the scope of this contribution, we would like to consider three main points: First, to boost digital (and covert) ethnography as a valuable method for research in cyberspace. Second, to create incentives for future research and for the contribution of scientific methods followed by other authors to enrich the discipline in this respect. Finally, to open up the discussion on the alignment of ethical criteria within digital ethnographic research intrinsic to Spanish criminology. 
Once the ethnographic phase of the project was completed, we reflected on the need for digital ethnography in our current environment. We see shifts in young peoples' attitudes and interactions by means of changes in technology and communication, for example, by Instagram. We are coming across increasingly more deaths by selfie (Molins 2018), given that we crave the immortality of the moment. People learn to practice sex through online porn and learn how to cook by watching YouTube videos. Our way of life has changed, so our way of carrying out research must also change. We must try to be flexible and swift in reacting as the current tide in which we move, and we have to constantly generate methodological strategies that are adapted to the phenomena and the objects of study. All this inescapably involves sharing knowledge within the scientific community itself, leaving to one side the old battles between schools or disciplines, and generating hybrid methods that allow us to capture the multifunctional essence of $21^{\text {st }}$ century social phenomena.

Adler, Peter and Adler, Patricia. 1994. "Observational technique." In Norman Denzin and Yvonna Lincoln (Eds). Handbook of Qualitative Research (1 ${ }^{\mathrm{a}}$ ed.), 377-392. California: Sage.

Amedie, Jacob. 2015. The Impact of Social Media on Society. In Advanced Writing: Pop Cultural Intersections, 2: 1-19.

Amnesty International. November 20, 2017. Amnistía revela alarmante impacto de los abusos contra las mujeres en Internet. Accessed 21 st May 2019: https:// www.amnesty.org/es/latest/news/2017/11/amnesty-reveals-alarming-impactof-online-abuse-against-women/

Angrosino, Michael. 2007. Doing Ethnographic and Observational Research. London: Sage.

Augé, Marc. 2008. Non-Places: Introduction to an Anthropology of Supermodernity. V Londors: New York.

Barbour, Rosaline. 2007. Doing Focus Group. London: Sage.

Bauman, Zygmunt. 2000. Liquid Modernity. London: Polity Press.

Baym, Nancy. 1999. Tune In, Log Out, Fandom, and Online Community. California: Sage.

Birtchnell, Thomas. and Caletrio, Javier. Eds. 2013. Elite Mobilities. London: Routledge.

Bloor, Michael and Ward, Fiona. 2006. Keywords in Qualitative Methods: A Vocabulary of Research Concepts. London: Sage.

Bourdieu, Pierre. 2004. Campo de poder, Campo Intelectual. Buenos Aires: Quadrata.

Bridle, James. 2018. New Dark Age. Technology and the End of the Future. London: Verso Books.

Briggs, Daniel. 2013. Deviance and risk on holiday. An Ethnography of British Tourists in Ibiza. London: Palgrave.

Briggs, Daniel and Gamero Monge, Ruben. 2017. Dead-end lives. Drugs and violence in the city shadows. London: Policy Press.

Briggs, Daniel. 2018. Commodifying Intimacy in 'Hard Times': A Hardcore Ethnography of a Luxury Brothel. Journal of Extreme Anthropology, 2(1): 66-68. 
Bryman, Alan. 2012. Social research methods. (4th. ed.). Oxford: Oxford University Press.

Butler, Judith. 1999. Gender trouble: feminism and subversion of identity. London: Routledge.

Byung-Chul, Han. 2017. Psycho-politics: Neoliberalism and New Technologies of Power. London: Verso.

Galvey, David. 2008. The Art and Politics of Covert Research. Doing 'Situated Ethics' in the Field. In Sociology, 42, 5, 905-918.

Galvey, David. 2013. Covert Ethnography in Criminology: a submerged yet creative tradition. Current Issues in Criminal Justice, 25(1): 541-550.

Cedeira, Brais. April 24, 2018. Se busca al asesino de Grindr que mató a este joven en Madrid tras engañarlo para tener sexo. El Español. Accessed on $21^{\text {st }}$ May 2019: https://www.elespanol.com/reportajes/20180423/busca-asesino-grindrjoven-madrid-enganarlo-tener/301970877_0.html

Glemens, Ghris. Atkin, David. and Krishnan, Archana. 2015. The influence of biology and personality traits on gratifications obtained through online dating websites. Comupters in Human Behaviour. 49: 120-129.

Clifford, James. 1983. On Ethnography Authority. In Representations, 2: 118-146.

Daniels, Jessie. Gregory, Karen. and McMillan Gottom, Tressie. (Eds) 2016. Digital Sociologies. Bristol: Bristol University Press.

De Cauter, Lieven. 2005. The Capsular Civilization: On the City in the Age of Fear. Amsterdam: NAi.

Díaz de Rada, Ángel. 2011. El taller del etnógrafo. Materiales y herramientas de investigación en etnografía. Madrid: UNED.

Ebo, Boshah. 1998. Internet or Outernet?. In Boshah Ebo (Ed.) Cyberghetto or Cybertopia? Race, Class, and Gender on the Internet. 1-12. Westport, CT: Praeger.

El Mundo. 2018. Generación Z. Contada por sí misma. Accessed on May 29th 2019: http://lab.elmundo.es/generacion-z/que-es.html

Estalella, Adolfo. 2018. Etnografías de lo digital: Remediaciones y recursividad del método antropológico. In Revista de Antropología Iberoamericana, 13, 1: 45-68.

Gehl, Robert. 2018. Power/freedom on the dark web: A digital ethnography of the Dark Web Social Network. In New Media and Society. 18, 7: 1219-1235.

Hall, Steve. Winlow, Simon and Ancrum, Graig. 2008. Criminal identities and consumer culture: Crime, exclusion and the new culture of narcissism. Devon: Willan Publishing.

Hall, Alexandra and Antonopoulos, Georgios. 2018. Fake meds online: the internet and the transnational market in illicit pharmaceuticals. London: Palgrave MacMillan.

Hammersley, Martin and Atkinson, Paul. 1994. Etnografía: Métodos de investigación. Barcelona: Paidós Ibérica.

Haraway, Donna. 1991. Simians, Gyborgs and Women: The reinvention of Nature. New York: Routledge.

Haywood, Ghris. 2018. Men, masculinity and contemporary dating. London: Palgrave MacMillan. 
Huber, Gregory and Malhotra, Neil. 2017. Political Homophily in Social Relationships: Evidence from Online Dating Behavior. The Journal of Politics. 71, 1: 269-283.

Hine, Christine. 2000. Virtual Ethnography. London: Sage.

Hine, Christine. 2015. Ethnography for the Internet. Embedded, embodied and everyday. London: Bloomsbury Academic.

Isabella, Simona. 2007. Ethnography of Online Role-Playing Games: The Role of Virtual and Real Contest in the Construction of the Field. Forum Qualitative Social Research, 8, 3, art. 36.

Ito, Mizuko. 1997. Virtually embodied: The reality of fantasy in a multiuser dungeon. In David Porter (ed.) Internet Culture, pp. 87-109. London: Routledge.

Kozinets, Robert. 2010. Netnography. Doing Ethnographic Research Online. London: Sage.

Kvale, Steinar. 2008. Doing interviews. London: Sage.

Lipovetsky, Giles. 2003. Le Luxe éternel : De l'âge du sacré au temps des marques, Paris: Gallimard.

Luego, Francisca. 2010. Masculinidades no dominantes: una etnografía de gaydar [TFM]. Accessed on May 21st 2019: http://repositorio.flacsoandes.edu.ec/ bitstream/10469/3273/1/TFLACSO-2010FLB.pdf

Lugosi, Peter. 2006. Between Overt and Covert Research. Concealment and Disclosure in an Ethnographic Study of Commercial Hospitality. In Qualitative Inquiry, 2, 3: 541-561.

Lyman, Peter and Wakeford, Nina. 1999. Going into the (virtual) field. In American Behavioral Scientist, 43, 3: 359-376.

Magnet, Soshana. 2007. 'Feminist Sexualities, Race and the Internet: An Investigation of Suicidegirls.Com'. New Media \& Society. 9, 4: 577-602.

Molins, Alberto. July 1, 2018. Causa de la muerte, una selfie. In La Vanguardia digital version. Accessed on 29th May 2019: https://www.lavanguardia.com/ vida/20180701/45527373074/muerte-selfie-india.html

Muñoz, Rúben. and Salinas, Claudia. 2018. La crisis de la autoridad del etnografiado. Metodologías encubiertas e investigación en derechos humanos y población vulnerable: Dos estudios de caso en México. In Revista Interdisciplinaria de Estudios de Género de El Colegio de México, 4: e158.

Oliviola, Ghristopher. Eastwick, Paul. Finkel, Eli. Hortaçu, Ali. Ariely, Dan. and Todorov, Alexander. 2015. First impressions and consumer mate impressions in online dating and speed dating. Advances in Consumer Research. 43: 51.55 .

Pink, Sarah. Horst H, Postill, John. Hjorth, Larissa. Lewis, Tania. and Tacchi, Jo. 2016. Digital Ethnography. Principles and Practice. London: Sage.

Ryan, Paul. 2019. Male sex workers in the Digital Age: Curate Lives. London: Palgrave MacMillan.

Silva Esquinas, Antonio. Pérez Suárez, Jorge Ramiro and Briggs, Daniel. 2018. El escuadrón suicida de la Criminología: Innovación etnográfica en contextos de ocio nocturno. Casos Magaluf y "raves". Archivos de Criminología, Seguridad Privada y Criminalística. XI, 21: 109-134. 
Sharp, Keith and Earle, Sarah. 2003. Cyberpunters and Cyberwhores: Prostitution on the Internet. In Yvonne Jewkes (Ed.) Dot.cons: Crime, Deviance and Identity on the Internet. 36-52. Cullompton, Devon: Willan Publishing.

Slater, Don. 1999. Trading Sexpics on IRC: Embodiment and Authenticity on the Internet. Body and Society. 4, 4: 91-117

Smith, Aaron and Duggan, Maeve. 2013. Online dating and relationships. Washington: Pew Research Centre of Internet and Technology.

Velasco, Honorio and de Rada, Ángel. 2009. La lógica de la investigación etnográfica: un modelo de trabajo para etnógrafos de la escuela $\left(6^{a}\right.$ ed.). Madrid: Editorial Trotta.

Winlow, Simon. 2001. Badfellas: Crime, Tradition and New Masculinities. London: Berg.

Xia, Peng. Lui, Benyuan. Sun, Yizou. And Ghen, Gindy. 2015. Reciprocal Recommendation System for Online Dating. Proceedings of the 2015 IEEE. 49: $1-26$.

Žižek, Slavoj. 2009. The Plague of Fantasies, London: Verso.

Antonio Silva Esquinas is finalizing his Masters in Anthropological Ethnography in Spain having done extensive observational research on the homeless, sex workers and domestic violence victims. He also has a side interest in social media and online identities hence his collaboration with the Research Group of Knowledge on Social Problems.

Rebeca Cordero Verdugo is a lecturer in Applied Sociology and has a $\mathrm{PhD}$ in Communication and Conflict. She teaches and researches the Research Group of Knowledge on Social Problems at the Universidad Europea and her research interests cover gender inequality, social injustice and, more recently, online applications and identities. She has published widely in Spain and is frequently asked to appear in media interviews about politics and women's' rights.

Jorge Ramiro Pérez Suárez is a lecturer in Criminology at Universidad Europea de Madrid and a researcher at the Research Group into Social Problems at the same university. His main area of research is the impact of technology in deviant behaviour, he has developed the concept of "Cyborg Criminology" in his book "We Are Cyborgs". He advocates for the use of Mixed Methods in the social sciences and has undertaken research on deviant leisure, cybercrime, police culture and online pornography.

Daniel Briggs is a consultant to the British Foreign and Commonwealth Office and part time lecturer in Criminology at the Universidad Europea in Madrid where he also leads the Research Group of Knowledge on Social Problems. His interests broadly cover any social problem and he has published extensively, most recently receiving an international award for his book Dead End Lives from the American Society of Criminology. He currently teaches and researches in Madrid, Spain and is completing other ethnographic research projects on the refugee crisis and luxury brothels. 